\title{
Involvement of angiotensin II receptor type 1/NF-кB signaling in the development of endometriosis
}

\author{
ZHIMIN ZHANG $^{1 *}$, YI YUAN ${ }^{2 *}$, LIAN HE $^{3}$, XIAOGUANG YAO ${ }^{3}$ and JINGWEI CHEN ${ }^{3}$ \\ ${ }^{1}$ Department of Obstetrics, The Fourth Hospital of Shijiazhuang City, Shijiazhuang, Hebei 050011; \\ ${ }^{2}$ Department of Obstetrics and Gynecology, Zhejiang Hospital, Hangzhou, Zhejiang 310030; \\ ${ }^{3}$ Hebei Key Laboratory of Integrative Medicine on Liver-Kidney Patterns, Institute of Integrative Medicine, \\ College of Integrative Medicine, Hebei University of Chinese Medicine, Shijiazhuang, Hebei 050200, P.R. China
}

Received August 5, 2019; Accepted June 24, 2020

DOI: $10.3892 / \mathrm{etm} .2020 .9071$

\begin{abstract}
Endometriosis (EM) is a common disease in women; however, the signaling pathways and related genes underlying the mechanisms of EM remain unclear. The present study aimed to investigate the role of angiotensin II receptor type 1 (AGTR1) in the pathogenesis of EM. Human EM tissues were collected, and the expression levels of AGTR1 and NF- $\kappa \mathrm{B}$ in the tissues were analyzed using immunochemistry and western blotting, while the estrogen levels in the EM tissues were determined by ELISA. In vitro human endometrial stromal cells were used to investigate the expression levels of AGTR1 following exposure to estrogen; the interaction between AGTR1 and NF- $\kappa \mathrm{B}$ was determined using reverse transcription-quantitative PCR and western blotting; and the effects of AGTR1 on cell proliferation, as well as the apoptotic and migratory abilities of the cells were evaluated using WST-1 assays, wound healing assays and flow cytometry, respectively. It was observed that both the expression levels of AGTR1 and the activity of $\mathrm{NF}-\kappa \mathrm{B}$ were increased in human EM tissues and stromal cells, and this activation of AGTR1 subsequently increased the activity of NF- $\kappa \mathrm{B}$. Moreover, estrogen was found to regulate the expression levels of AGTR1 in stromal cells. The activation of AGTR1 was demonstrated to promote cell proliferation and migration, in addition to preventing cells from undergoing apoptosis. In conclusion, the present study suggested that the increased activity of the AGTR1-NF- $\mathrm{B}$ axis following the decreased exposure to estrogen may be
\end{abstract}

Correspondence to: Dr Jingwei Chen, Hebei Key Laboratory of Integrative Medicine on Liver-Kidney Patterns, Institute of Integrative Medicine, College of Integrative Medicine, Hebei University of Chinese Medicine, 3 Xingyuan Road, Shijiazhuang, Hebei 050200, P.R. China

E-mail: drjingweichen@outlook.com

${ }^{*}$ Contributed equally

Key words: angiotensin II receptor type 1, endometriosis, NF-кB, stromal cells important for the pathogenesis of EM. In addition, AGTR1 may be a potential therapeutic target for the treatment of EM.

\section{Introduction}

Endometriosis (EM) is a disorder in which endometrial tissue grows outside of the uterine cavity, such as within the fallopian tubes or peritoneum (1). It has been suggested that EM affects $6-10 \%$ of women of reproductive age in the USA, whilst in the clinic,EMisdiagnosedin $4 \%$ of women undergoing tuballigation and $50 \%$ of teenagers with intractable dysmenorrhea (2). EM is generally considered as an inflammatory, estrogen-related disease that can induce numerous symptoms in patients, including pelvic pain or infertility; however, the pathogenesis of EM remains relatively unclear. The most current hypothesis is that EM occurs following retrograde menstruation, which suggests that menstrual uterine contractions stimulate the reflux of endometrial tissue into the fallopian tubes and peritoneal cavity. However, retrograde menstruation is observed in 76-90\% of women during menstruation, whereas EM only affects $6-10 \%$ of women of reproductive age (3). Recent molecular cytogenetic studies have provided novel evidence suggesting that acquired alterations in specific genes or signaling pathways may induce EM $(4,5)$. In fact, in a previous study, through reanalyzing multiple genetic datasets of EM, it was identified that numerous important genes may contribute to the pathogenesis of EM, including angiotensin II receptor type 1 (AGTR1), membrane metalloendopeptidase, myosin heavy chain 11 and 15-hydroxyprostaglandin dehydrogenase (6). These genes regulate pathways involved in the renin-angiotensin system (RAS), smooth muscle contraction, lipoxin synthesis and the NF- $\mathrm{NB}$ signaling pathway (6). AGTR1 is a gene coding receptor for angiotensin II (AngII) and is considered to mediate major cellular events; for example, AGTR1 was reported to be expressed in human epithelial ovarian carcinoma (7), and it was found to be involved in the invasion, migration and tumorigenesis of endometrial carcinoma (8). Notably, in a genome-wide association study, Hsieh et al (9) identified polymorphisms in the AGTR1 gene in EM. In addition, AGTR1 activation has also been observed to induce inflammation through the increased expression of leukocytic and endothelial adhesion molecules and the 
increased production of pro-inflammatory mediators (10). It is widely accepted that inflammation serves an important role in the pathogenesis and symptoms of EM.

$\mathrm{NF}-\kappa \mathrm{B}$ is a well-established pathway that participates in the inflammatory response, and previous studies have reported the activation of the NF- $\mathrm{B}$ signaling pathway in EM. For example, Wei and Shao (11) suggested that the activation of the NF- $\kappa \mathrm{B}$ signaling pathway promoted the development of EM, while Taniguchi et al (12) suggested that activated NF- $\mathrm{B}$ signaling may contribute to EM through inhibiting apoptosis in endothelial cells.

Therefore, in the present study, AGTR1 expression levels and the activity of NF- $\kappa$ B in human EM tissues were investigated. AGTR1 expression levels were significantly increased in human EM tissues, and in vitro, it was demonstrated that the increased expression levels of AGTR1 were in response to the inhibition of the estrogen receptor. AGTR1 was observed to activate the $\mathrm{NF}-\kappa \mathrm{B}$ signaling pathway, and promote cell viability and migration, whilst preventing apoptosis in EM cells, which may contribute to EM development.

\section{Materials and methods}

Patient studies. Study protocols involving human subjects were approved by the Institutional Ethics Committee of the Fourth Hospital of Shijiazhuang City, and written informed consent was obtained from all subjects. From June 2017 to December 2018, 34 women with EM were recruited to this study from the Fourth Hospital of Shijiazhuang City; however, 2 cases withdrew, 6 cases were confirmed to not have EM by laparoscopy and 9 cases were excluded due to the quality control of the samples. In the control group, 32 patients were recruited in the Fourth Hospital of Shijiazhuang City; however, 5 cases withdrew and 6 cases were excluded due to the quality control of the samples. Altogether, 17 patients (age, 22-38 years old) with EM with ovarian endometriotic cysts and 21 controls (age, 23-36 years old) were enrolled in the present study. The collected tissues were histologically confirmed by pathologists. Data concerning the patients' menstrual cycle phases were collected by $\mathrm{ZZ}$, YY and LH, and were classified into the proliferative phase (days 1-14) and the secretory phase (days 15-29). The exclusion criteria of this study included patients who received hormonal treatment or any anti-inflammatory treatment for $\geq 6$ months prior to surgery.

Cell culture and reagents. Human endometrial stromal cells (ESCs) (cat. no. CRL-4003) were purchased from the ATCC. ESCs were maintained in DMEM (Gibco; Thermo Fisher Scientific, Inc.), supplemented with 10\% FBS (Gibco; Thermo Fisher Scientific, Inc.) treated with dextran-coated charcoal (final concentration, 0.25\%; Sigma-Aldrich; Merck KGaA), to remove any hormonal effects from the contents of FBS; $100 \mathrm{U} / \mathrm{ml}$ penicillin (Invitrogen; Thermo Fisher Scientific, Inc.); and $10 \mathrm{mg} / \mathrm{ml}$ streptomycin (Invitrogen; Thermo Fisher Scientific Inc.), and maintained at $37^{\circ} \mathrm{C}$ and $5 \% \mathrm{CO}_{2}$.

Losartan potassium (AGTR1 antagonist) dissolved in DMSO, AngII (AGTR1 activator) (13), estrogen (17 $\beta$-estradiol) and tamoxifen (the estrogen receptor modulator) in DMSO $(14,15)$ were purchased from Sigma-Aldrich. Tamoxifen is an estrogen receptor modulator (16). Cells were treated with tamoxifen to investigate the effect of estrogen on cells when its receptor was regulated by tamoxifen. Cells were also treated with $17.9 \mathrm{nM}$ TPCA-1 in DMSO (Selleck Chemicals) (17), which is a selective inhibitor of IKK $\beta$ (IкB kinase $\beta$ ). ESCs were divided into the various treatment groups as follows: i) $10 \mu \mathrm{M}$ AngII; ii) $10 \mu \mathrm{M}$ AngII+10 $\mu \mathrm{M}$ losartan potassium; iii) $10 \mu \mathrm{M}$ losartan potassium; iv) $10 \mathrm{nM}$ $17 \beta$-estradiol; v) $10 \mathrm{nM} 17 \beta$-estradiol+10 $\mu \mathrm{M}$ tamoxifen; vi) $10 \mu \mathrm{M}$ tamoxifen; vii) $10 \mu \mathrm{M}$ AngII+17.9 nM TPCA-1; viii) $17.9 \mathrm{nM}$ TPCA-1; ix) DMSO (controls).

Immunohistochemistry (IHC). Endothelium tissue was fixed with $10 \%$ formalin for $24 \mathrm{~h}$ at room temperature, and embedded in paraffin. Paraffin-embedded tissue samples were cut into 5- $\mu \mathrm{m}$ thick sections. The tissue sections were subsequently deparaffinized with xylene at $55^{\circ} \mathrm{C}$ and rehydrated with descending alcohol series, and then subjected to antigen retrieval. Deparaffinized sections were blocked with 5\% goat serum (Thermo Fisher Scientific, Inc.) at room temperature for $1 \mathrm{~h}$. Tissue sections were incubated with a primary rabbit monoclonal antibody targeting AGTR1 (1:200; Abcam; cat. no. ab124734) overnight at $4^{\circ} \mathrm{C}$. Following the primary incubation, sections were incubated with an anti-rabbit horseradish peroxidase-conjugated secondary antibody (1:8,000; Abcam, cat. no. ab99702) at room temperature for $1 \mathrm{~h}$. The slides were subsequently stained with 3,3'-diaminobenzidine, counterstained with hematoxylin $(0.5 \%)$ and visualized using a light microscope (Olympus Corporation). Expression levels were semi-quantified according to the regular IHC staining grade system (18).

Reverse transcription-quantitative PCR (RT-qPCR). Total RNA was extracted from ESCs or tissues using a RNeasy kit (Qiagen, Inc.) following the manufacturer's instructions. Total RNA (500 ng) was reverse transcribed into cDNA using SuperScript $^{\mathrm{TM}}$ III Reverse Transcriptase (Invitrogen; Thermo Fisher Scientific, Inc.). qPCR (SYBR ${ }^{\mathrm{TM}}$ Green; Thermo Fisher Scientific, Inc.; cat. no. 4309155) was subsequently performed using an ABI PRISM 7500 Real-Time PCR System (Applied Biosystems; Thermo Fisher Scientific, Inc.), according to the manufacturer's protocol. Cycling conditions for the reaction were as follows: An initial hold for $10 \mathrm{~min}$ at $95^{\circ} \mathrm{C}$; then 40 cycles of $15 \mathrm{sec}$ at $95^{\circ} \mathrm{C}$ denaturation, $30 \mathrm{sec}$ at an annealing temperature of $60^{\circ} \mathrm{C}$ and a $30 \mathrm{sec}$ extension at $72^{\circ} \mathrm{C}$. The following primer pairs were used for the qPCR: $\beta$-actin forward, 5'-CATGTACGTTGCTATCCAGGC-3' and reverse, 5'-CTCCTTAATGTCACGCACGAT-3'; and AGTR1 forward, 5'-ATTTAGCACTGGCTGACTTATGC-3' and reverse, 5'-CAGCGGTATTCCATAGCTGTG-3'. Gene expression levels were quantified using the $2^{-\Delta \Delta \mathrm{Cq}}$ method (19) and normalized to the internal reference gene $\beta$-actin. Each experiment was performed in triplicate.

Western blotting. Total protein was extracted from tissues or ESCs using RIPA lysis buffer (Beyotime Institute of Biotechnology; cat. no. P0013B) containing proteinase inhibitor (Beyotime Institute of Biotechnology; cat. no. P1006). Total protein was quantified using BCA assays, and $20 \mu \mathrm{g}$ protein/lane was separated by $8-10 \%$ SDS-PAGE. The separated proteins were subsequently electrotransferred onto 
PVDF membranes (EMD Millipore) and blocked with 5\% bovine serum albumin for $1 \mathrm{~h}$ at room temperature. (Beyotime Institute of Biotechnology; cat. no. ST023-50 g). The membranes were incubated with the following primary antibodies (all 1:3,000) at $4^{\circ} \mathrm{C}$ overnight: Anti-AGTR1 (Abcam; cat. no. ab124734), anti-p65 (Santa Cruz Biotechnology, Inc.; cat. no. sc-109), anti-phosphorylated (pho)-p65 (Ser536; Santa Cruz Biotechnology, Inc.; cat. no. sc-101752) and anti- $\beta$-actin (Santa Cruz Biotechnology, Inc.; cat. no. sc-7210). Following the primary antibody incubation, membranes were incubated with anti-rabbit horseradish peroxidase-conjugated IgG secondary antibodies (1:3,000; Abcam; cat. no. ab99702) at room temperature for $1 \mathrm{~h}$. Protein bands were visualized using the Western Bright ECL kit (Bio-Rad Laboratories, Inc.). $\beta$-actin was used as the loading control. The protein expression levels were quantified with ImageJ software (version 1.8.0; National Institutes of Health).

Wound healing assay. To evaluate cell migration, ESCs were seeded into 12 -well plates $\left(0.1 \times 10^{6}\right.$ cells per well $)$ and cultured in DMEM supplemented with $10 \%$ FBS until reaching $100 \%$ confluence at $37^{\circ} \mathrm{C}$. Next, DMEM was removed, and a P-200 pipette tip was used to scratch a straight line into the cell monolayer. Cells were subsequently washed with PBS to remove the cell debris. Cells were then cultured with serum-free DMEM supplemented with $10 \mu \mathrm{M}$ losartan potassium, $10 \mu \mathrm{M}$ AngII or $17.9 \mathrm{nM}$ TPCA-1 depending on the treatment group at $37^{\circ} \mathrm{C}$ for $72 \mathrm{~h}$. Cells were photographed at 0 and $72 \mathrm{~h}$ using a light microscope (Olympus Corporation), magnification x100, and the wound closure was quantitatively analyzed. The size of the regions with and without cells were quantitatively evaluated with ImageJ software (Version 1.8.0; National Institutes of Health) and used calculating the percentage wound closure.

Cell transfection. A total of $10^{5} \mathrm{ESCs} /$ well were seeded into 12-well culture plates and transfected with $40 \mathrm{nM}$ small interfering RNA (siRNA) targeting AGTR1 (5'-CUGUAG AAUUGCAGAUAUU dTdT-3', 3'-dTdT GACAUCUUAACG UCUAUAA-5) or a scrambled control (5'-UUCUCCGAACGU GUCACGUdTdT-3'; 3'-dTdT AAGAGGGUUGCACAGUGG A-5', negative control; Santa Cruz Biotechnology, Inc.) using Lipofectamine ${ }^{\circledR} 2000$ reagent (Invitrogen; Thermo Fisher Scientific, Inc.), according to the manufacturer's protocol. Following $24 \mathrm{~h}$ of transfection, RT-qPCR and western blotting were performed to prove the successful transfection, and then the ESCs were used for subsequent experiments.

Flow cytometric analysis of apoptosis. Flow cytometry was used to investigate the levels of apoptosis in ESCs in vitro. Following treatment, ESCs were treated with $0.25 \%$ trypsin and then gently centrifuged at $1,000 \mathrm{x}$ g for $5 \mathrm{~min}$ at room temperature. The collected ESCs were washed with PBS. The cells were subsequently resuspended in $500 \mu \mathrm{l}$ binding buffer containing $5 \mu \mathrm{l}$ Annexin V-FITC and $10 \mu \mathrm{l}$ propidium iodide using the Annexin V-FITC Apoptosis Detection kit (Bio-Rad Laboratories, Inc.). Following incubation for $30 \mathrm{~min}$ in the dark at room temperature, apoptotic cells were subsequently analyzed using a BD FACScan ${ }^{\mathrm{TM}}$ flow cytometer (BD Biosciences). Data were analyzed using FlowJo software (version 7.6.5; FlowJo, LLC).
Cell proliferation assay. A total of $5 \times 10^{3}$ cells/well were seeded into 96 -well plates and were cultured for $72 \mathrm{~h}$ at $37^{\circ} \mathrm{C}$. Cellular proliferation was subsequently analyzed using a WST-1 assay (Roche Diagnostics), according to the manufacturer's protocol. The absorbance was measured at $440 \mathrm{~nm}$ using a multimode plate reader.

ELISA. The hormone expression levels of estrogen (cat. no. K4267-100; BioVision,Inc.), progesterone (cat.no. MBS494530; MyBioSource, Inc.) and prolactin (cat. no. MBS580135; MyBioSource, Inc.) in endometrial tissue ( $1 \mathrm{~g})$ were determined using ELISA kits, according to the manufacturers' protocols. Briefly, the frozen tissues were homogenized using a sonicator $(20 \mathrm{kHz} / \mathrm{s})$ and were subsequently centrifuged for $5 \mathrm{~min}$ at $5,000 \mathrm{xg}$ at $37^{\circ} \mathrm{C}$ to obtain the supernatant, which was then suspended in PBS and added in the plates (100 $\mu \mathrm{l} /$ well). A total of $0.1 \mathrm{ml}$ biotinylated antibodies (1:100) against the target hormones and the extracts from tissues were then added to the plate. Standard reagents as the per the ELISA kits were diluted and added to the wells to generate a standard curve. Following incubation for $2 \mathrm{~h}$ at room temperature, the absorbance was measured at $450 \mathrm{~nm}$ using a multimode plate reader.

Statistical analysis. All the data were analyzed and graphics produced using $\mathrm{R}$ (version 3.6.2). Data are presented as the mean \pm SEM of three independent experimental repeats. Statistical differences between $>2$ groups were determined using one-way ANOVA with Tukey's post hoc test, whereas differences between 2 groups were determined using Student's t-test. Correlation analysis was performed using Pearson's correlation test. $\mathrm{P}<0.05$ was considered to indicate a statistically significant difference.

\section{Results}

Increased AGTRl and $N F-\kappa B$ expression levels are present in human EM tissues. AGTR1 expression levels in EM tissues were determined using IHC. Compared with that of normal endometrial tissues (control), Immunohistochemical staining showed that there were numerous brown red immunoreactive particles of AGTR1 distributed densely in stromal cells and glandular epithelial cells in the endometrium. The expression levels of AGTR1 in EM tissues were significantly increased compared with those of the control tissues (Fig. 1A). Subsequently, the mRNA expression levels of AGTR1 in EM tissues were evaluated using RT-qPCR, and it was demonstrated that AGTR1 expression levels were significantly increased in EM tissue compared with those in control tissue (Fig. 1B).

Previously, multiple studies have reported that estrogen serves a critical role in the development of EM (20). In the present study, the levels of estrogen, progesterone and prolactin in both EM and normal tissues were investigated, and it was observed that the levels of estrogen in EM tissues were significantly decreased compared with those in control tissues (Fig. S1). Moreover, the levels of estrogen in EM were negatively correlated with the expression levels of AGTR1 (Fig. 1C). However, the results also demonstrated that there was no significant difference between the levels of progesterone or prolactin found in EM tissues and those found in control 
A

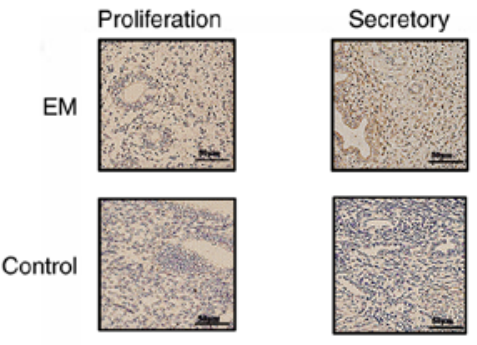

B

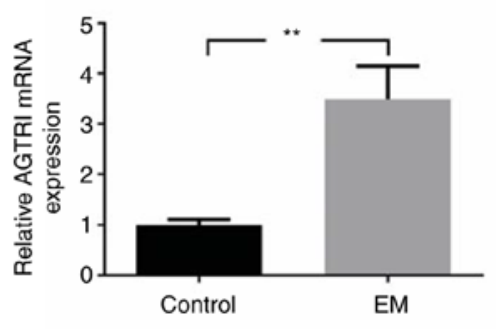

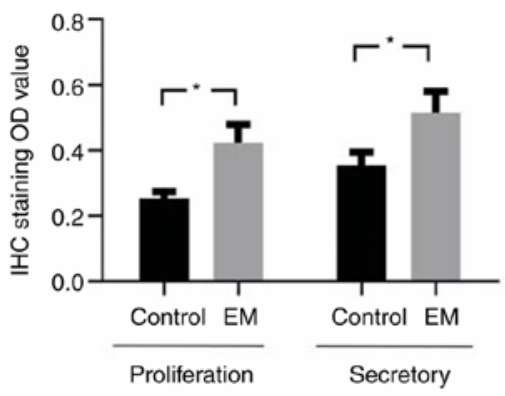

C

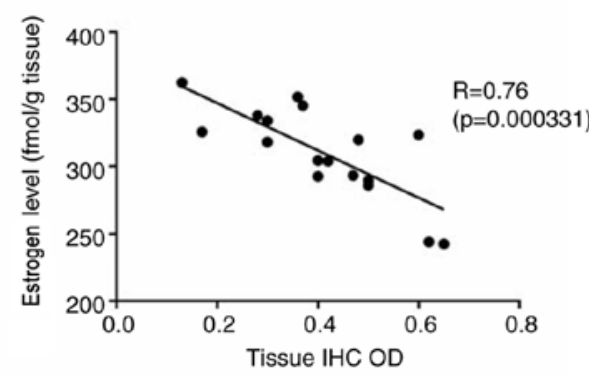

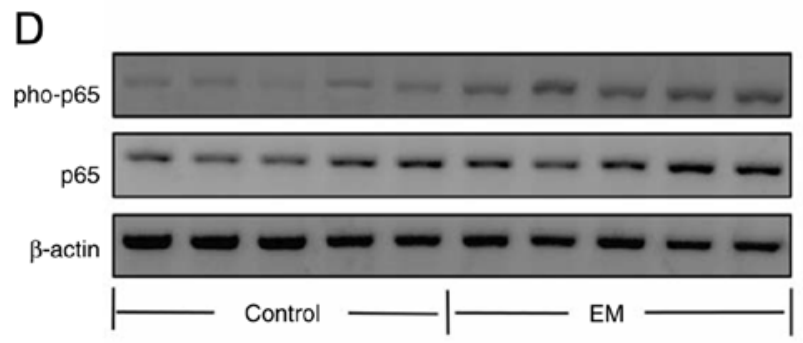

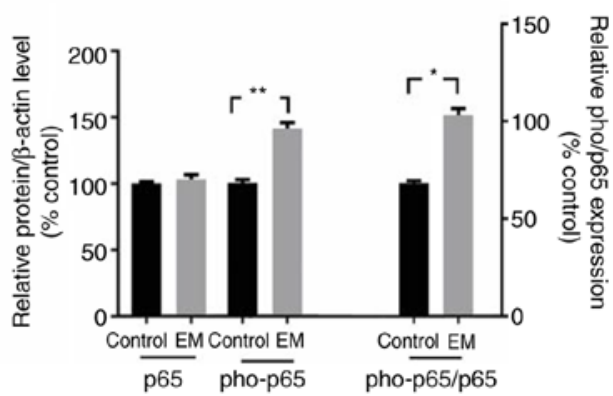

Figure 1. Expression levels of AGTR1, NF- $\mathrm{BB}$ activity and estrogen levels in human EM tissues. (A) IHC staining was performed to determine the expression levels of AGTR1 in human EM tissues $(n=17)$ and normal endometrium tissues $(n=21)$ in the proliferative phase and secretory phase. AGTR1 expression levels were significantly increased in EM compared with those in normal tissues during the menstrual cycle. The expression levels were semi-quantified according to the regular IHC staining grade system (17). Scale bar, $50 \mu \mathrm{m}$. (B) The expression levels of AGTR1 were assessed using reverse transcription-quantitative PCR; AGTR1 mRNA expression levels were increased in EM tissue compared with those in control tissue. The expression of AGTR1 was normalized to that of $\beta$-actin. (C) Correlation analysis of AGTR1 protein expression levels with estrogen levels in EM. A significant, negative correlation between AGTR1 protein expression levels (IHC OD value) and estrogen levels were observed in the tissues. The level of estrogen was evaluated by ELISA. (D) The activity of NF- $\kappa B$ was analyzed using western blotting. The expression levels of pho-p65 and the pho-p65/p65 ratio were increased in EM compared with the values in control tissues. Data are presented as the mean \pm SEM. ${ }^{*} \mathrm{P}<0.05,{ }^{* *} \mathrm{P}<0.01$. EM, endometriosis; AGTR1, angiotensin II receptor type 1; IHC, immunohistochemistry; OD, optical density; pho, phosphorylated.

tissues (Fig. S1). Notably, the ratio of estrogen/progesterone was significantly decreased in EM tissues compared with that of control tissues (Fig. S1).

In addition, NF- $\mathrm{KB}$ activity in EM was investigated using western blotting, and the data revealed that pho-p65 expression levels (the ratio of pho-p65:p65) were significantly increased in EM tissues compared with those in control tissues (Fig. 1D).

AGTR1 promotes the activity of $N F-\kappa B$. The effect of AGTR1 on the NF- $\kappa \mathrm{B}$ signaling pathway in ESCs was subsequently investigated. In vitro, losartan treatment significantly decreased the expression levels of pho-p65 (the ratio of pho-p65:p65) in ESCs compared with those of untreated control cells, which suggested that AGTR1 antagonist may exert an inhibitory effect on the NF- $\kappa B$ signaling pathway (Fig. 2A). By contrast, ESCs treated with AngII, an activator of AGTR1 (21), exhibited significantly increased pho-p65 expression levels (the ratio of pho-p65:p65) compared with those of control cells, and the upregulation effect of AngII on pho-p65 was attenuated by losartan (Fig. 2A) when cells were treated with AngII in combination with losartan. In addition, following the genetic knockdown of AGTR1 expression in ESCs using siRNA (Fig. 2B and C), the expression levels of pho-p65 (the ratio of pho-p65:p65)were observed to be significantly decreased compared with those of scramble-treated cells (Fig. 2C).

Estrogen inhibits the expression levels of AGTR1. This study found that estrogen and AGTR1 levels were negatively correlated in EM. It was subsequently identified that the loss of estrogen expression could significantly increase AGTR1 expression levels; upon culturing ESCs and subsequently treating them with estrogen in vitro, it was discovered that estradiol treatment significantly decreased the expression levels of AGTR1 compared with those of the control, whereas the inhibition of AGTR1 expression by estrogen could be alleviated using the estrogen receptor modulator tamoxifen (Fig. 3), when cells were treated with estrogen combination with tamoxifen. Tamoxifen also increased the expression levels of AGTR1 compared with those of the control. 
A
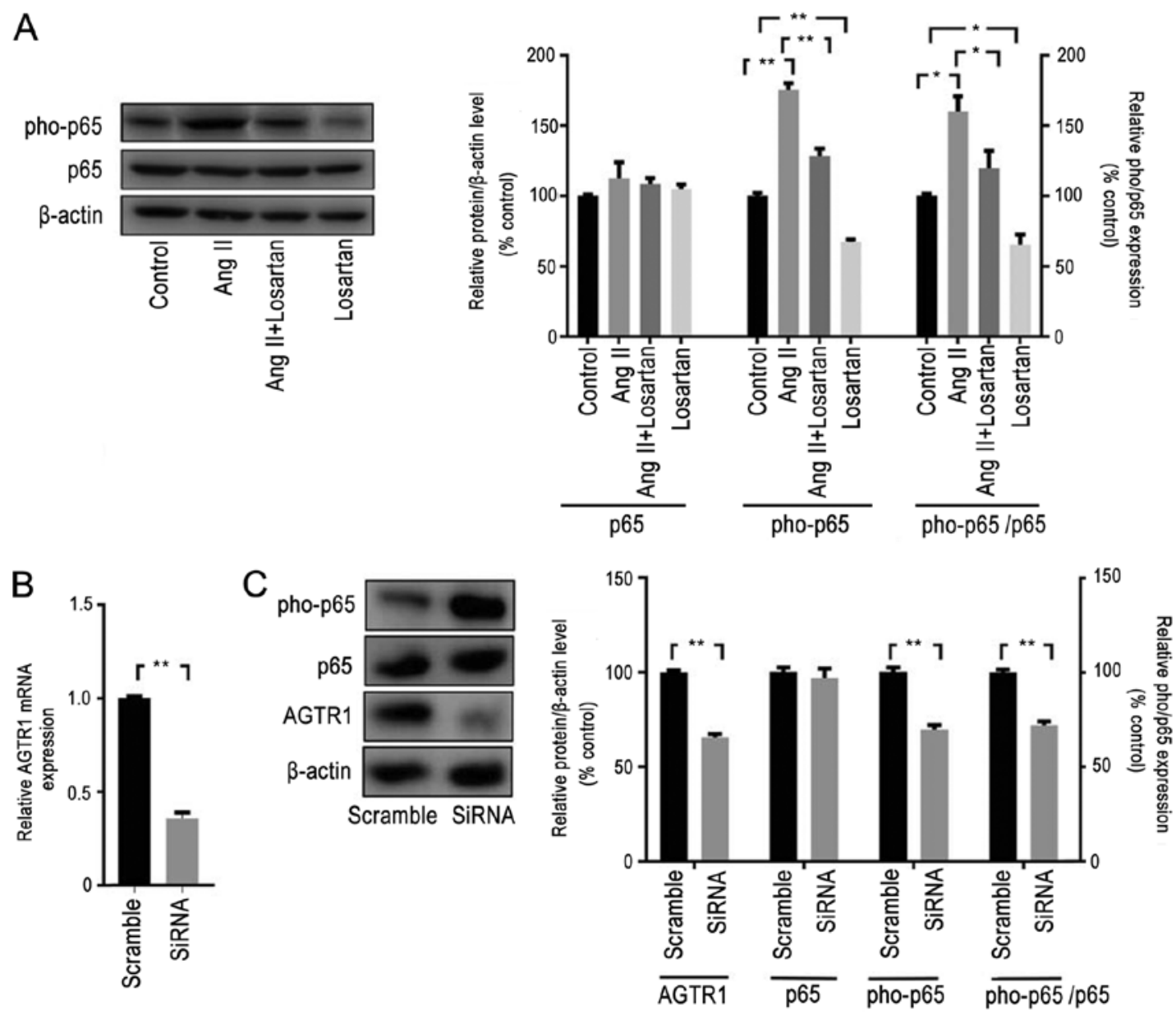

Figure 2. AGTR1 expression promotes the activity of NF-kB in ESCs. (A) ESCs were exposed to AngII, losartan or DMSO for $72 \mathrm{~h}$, and expression levels of pho-p65 were analyzed using western blotting. Activation of AGTR1 by AngII increased the expression levels of pho-p65, which was inhibited by losartan treatment. (B) AGTR1 expression was knocked down using siRNA. The expression levels of AGTR1 were analyzed using reverse transcription-quantitative PCR; siRNA significantly decreased AGTR1 expression. (C) The expression levels of ATGR1 and pho-p65 were determined using western blotting. siRNA decreased the phosphorylation of p65 and the pho-p65/p65 ratio, as well as the expression levels of ATGR1. All experiments were performed in triplicate, and data are presented as the mean $\pm \mathrm{SEM} .{ }^{*} \mathrm{P}<0.05,{ }^{* *} \mathrm{P}<0.01$. AGTR1, angiotensin II receptor type 1; pho, phosphorylated; siRNA, small interfering RNA; ESCs, endometrial stromal cells; AngII, angiotensin II.

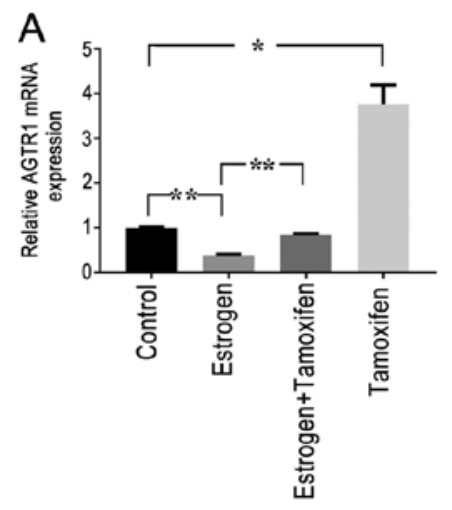

B
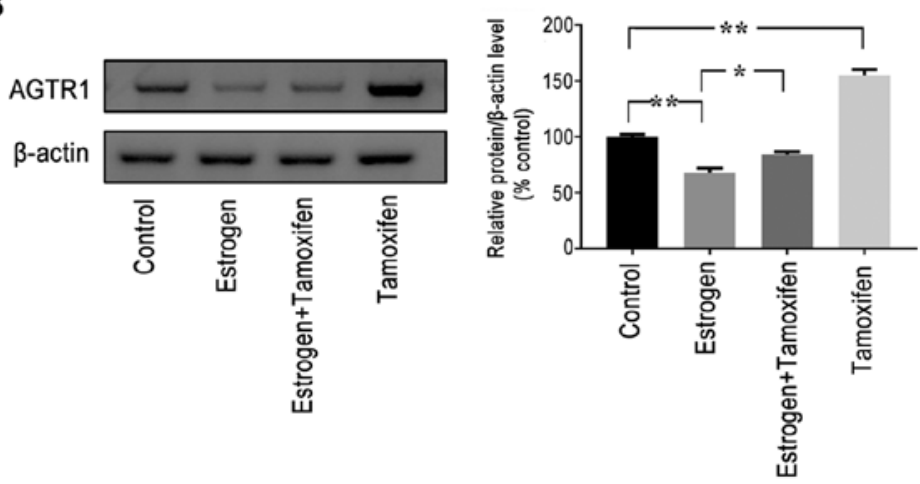

Figure 3. Estrogen regulates the expression levels of AGTR1 in ESCs. (A and B) ESCs were treated with estrogen or tamoxifen for $72 \mathrm{~h}$ and then collected to determine the expression levels of AGTR1 using (A) reverse transcription-quantitative PCR and (B) western blotting. The results revealed that the expression levels of AGTR1 were significantly decreased in cells treated with estrogen but increased in cells treated with the estrogen receptor modulator tamoxifen both at the mRNA and protein level. All experiments were performed in triplicate, and data are presented as the mean \pm SEM. ${ }^{*} \mathrm{P}<0.05,{ }^{* *} \mathrm{P}<0.01$. AGTR1, angiotensin II receptor type 1; ESCs, endometrial stromal cells.

AGTR1 promotes cell migration and proliferation, and inhibits apoptosis in ESCs through the NF- $\mathrm{KB}$ signaling pathway. The effects of AGTR1 on the migration of ESCs were investigated using wound healing assays. Pre-treatment with AngII for $72 \mathrm{~h}$ resulted in a significant increase in cell migratory ability compared with that of the control group; 

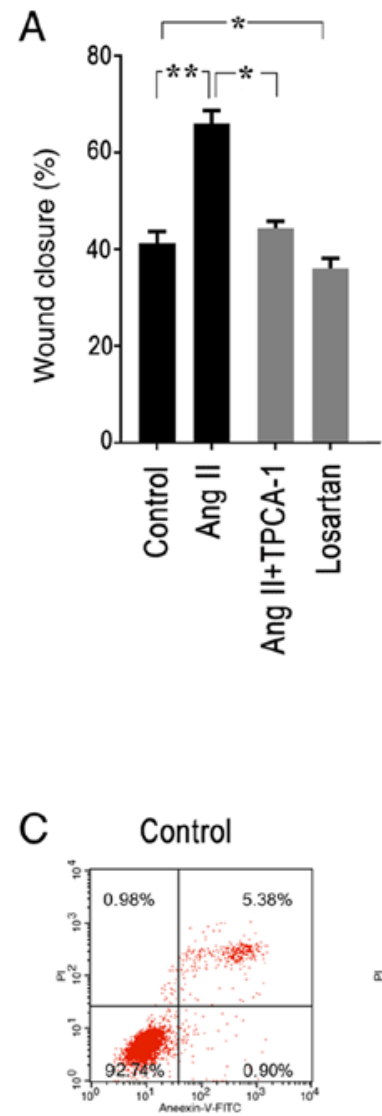

Ang II+TPCA-1

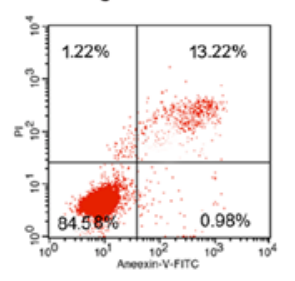

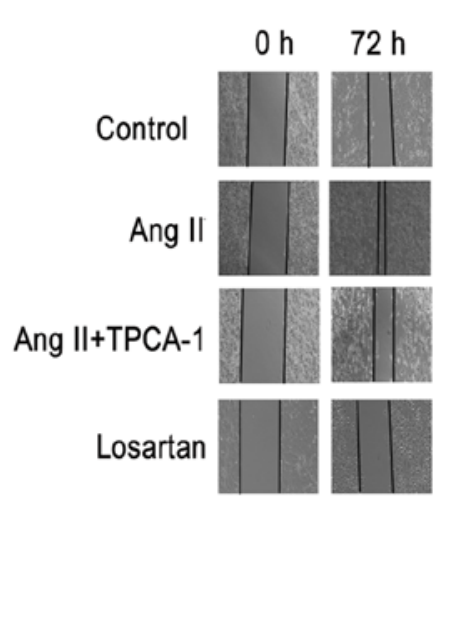

$\mathrm{B}$
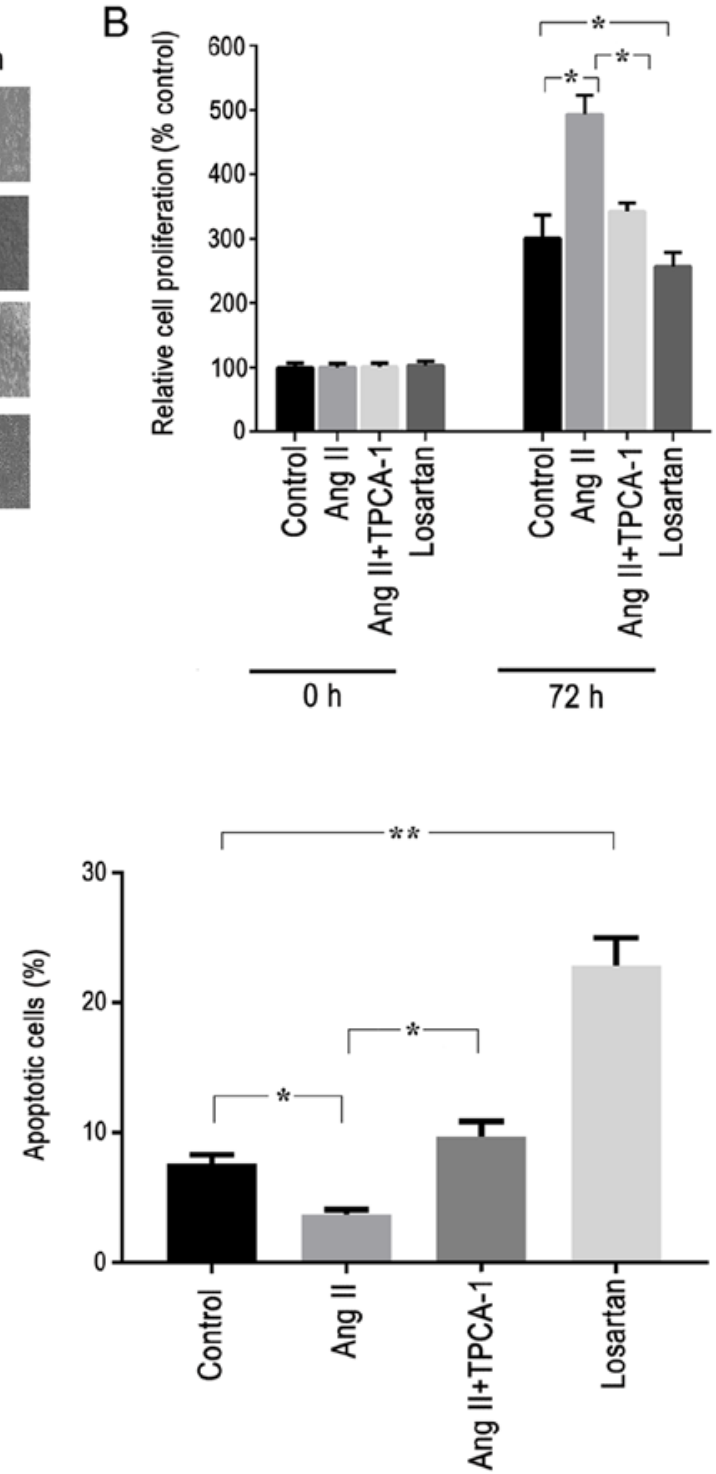

Figure 4. Activation of AGTR1 promotes cell proliferation and migration, and prevents apoptosis in ESCs in vitro via the NF- $\mathrm{kB}$ signaling pathway. ESCs were treated with AngII (AGTR1 activator), TPCA-1 (selective inhibitor of IкB kinase $\beta$ ), losartan (AGTR1 antagonist) or DMSO (control) for $72 \mathrm{~h}$ in vitro, and cell proliferation, apoptosis and migration were analyzed. (A) Wound healing assay was performed, and images were acquired using light microscopy (magnification, 100x). The activation of AGTR1 promoted wound closure, which was blocked by TCPA-1. Losartan significantly inhibited cell migration compared with that of the control. (B) Cell proliferation assay. The activation of AGTR1 by AngII increased cell proliferation compared with that of the control, whereas TPCA-1 inhibited the cell proliferation induced by AngII. Losartan also inhibited the cell proliferation. (C) Cell apoptosis assay. Following treatment for $72 \mathrm{~h}$ in vitro, ESCs were collected, stained with Annexin-V and PI, and analyzed by flow cytometry. The number of apoptotic cells (Annexin V-positive cells) was determined as the percentage of gated cells at upper-right and lower-right quadrants. Representative images and relative quantifications are shown. The results indicated that the activation of AGTR1 by AngII inhibited cell apoptosis, whereas the anti-apoptotic effect was inhibited by TPCA-1. Losartan promoted the apoptosis of cells. All experiments were performed in triplicate, and the data are presented as the mean $\pm \mathrm{SEM}$. "P<0.05, ${ }^{\text {** }} \mathrm{P}<0.01$. ESCs, endometrial stromal cells; AGTR1, angiotensin II receptor type 1; AngII, angiotensin II; PI, propidium iodide.

however, this effect was significantly prevented following treatment with TPCA-1, an antagonist of the signaling NF- $\mathrm{kB}$ pathway (Figs. 4A and S2A). In addition, losartan treatment also significantly decreased the migratory ability of ESCs compared with that of the control group (Fig. 4A).

To investigate the role of AGTR1 on the proliferative activity of ESCs, cell proliferation and apoptosis assays were conducted. The cells were cultured for $72 \mathrm{~h}$ in the presence of AngII, TPCA-1 or losartan. ESCs treated with AngII exhibited a significantly increased proliferative rate compared with that of the control group, alongside a significantly decreased apoptotic rate (Fig. 4B and C). By contrast, TPCA-1 treatment significantly blocked the effects of AngII on ESCs (Figs. 4B, C, S2B and C). ESCs treated with losartan or TPCA-1 displayed significantly decreased proliferation rates and increased apoptotic rates compared with those of the control group (Fig. 4B and C).

\section{Discussion}

AGTR1 is a component of the RAS, and has been reported to be upregulated in EM $(6,21)$. In the present study, decreased levels of estrogen in EM tissues were found to be associated with increased expression levels of AGTR1, which in turn promoted cell proliferation and prevented cell apoptosis 
through the activation of the NF- $\mathrm{B}$ signaling pathway. In the RAS, bioactive effector molecules, AngI and AngII serve antagonistic roles by binding to different receptors, namely AGTR1, AGTR2, respectively (22), which subsequently exert vasoactive or proliferative roles. In recent years, increasing attention has been paid to the local activity of the RAS in ovarian and endometrial tissues, which may subsequently contribute to physiological and pathological processes such as follicle maturation, regulation of reproduction, angiogenesis and tumor cell proliferation (23-25). Notably, the dysregulation of the RAS has been observed in EM; for example, Abraham et al (26) reported that, in rat endometrial stromal cells, AngII induced Cyclooxygenase-2 gene expression by activating the calcineurin/NFAT signaling pathway. In another study, Kowalczyńska et al (27) investigated the polymorphisms in the angiotensin I converting enzyme (ACE) gene and AGTR1 in women with EM, and their results indicated that the A2350G polymorphism in the ACE gene was associated with the development of EM. Nakao et al (28) discovered that the expression of AGTR1 was largely located in endometrial glandular epithelium and stromal cells, and AGTR1 expression levels were markedly increased in EM compared with those of normal tissue. Therefore, these findings suggested that the increased expression levels of AGTR1 may increase RAS sensitivity in endothelium tissue, and the subsequent activation of the RAS-AGTR1 system may promote the pathogenesis of EM.

The NF- $\kappa$ B family represents a family of transcription factors that serve vital roles in various processes such as cellular survival, proliferation and differentiation. Furthermore, the NF- $\kappa \mathrm{B}$ signaling pathway has been found to regulate menstruation (20). King et al (29) reported that I $\mathrm{B}$ kinase $\alpha$ and TANK Binding Kinase 1 mRNA expression levels were increased in the human endometrium during the perimenstrual phase of the menstrual cycle in response to premenstrual progesterone withdrawal. In addition, a previous study have demonstrated the constitutive activation of $\mathrm{NF}-\kappa \mathrm{B}$ in endometriotic lesions (30). The activation of the NF- $\kappa \mathrm{B}$ signaling pathway induces the production of pro-inflammatory cytokines such as IL-8 and matrix metalloproteinases, which subsequently induce tissue breakdown (31). Nie et al (32) reported the expression of $\mathrm{NF}-\kappa \mathrm{B}$ in the eutopic endometrium of patients with adenomyosis, which reportedly increased the expression of nuclear p65 and p52, whilst decreasing the expression of progesterone receptor B and cytoplasmic I $\kappa \mathrm{B} \alpha$. Park et al (33) reported that the expression levels of $\mathrm{NF}-\kappa \mathrm{B}$ p65 were increased in the eutopic endometrium and adenomyosis nodules of women with adenomyosis, which strongly suggested that $N F-\kappa B$ served a critical role in the pathogenesis and pathophysiology of adenomyosis. Finally, Wei and Shao (11) observed that blocking NF- $\kappa$ B activity with nobiletin reduced the lesion size and pain in a mouse model of EM. In the present study, the activation of AGTR1 in EM increased the activity of NF- $\mathrm{B}$, and subsequently promoted cell proliferation and migration. The interaction between AGTR1 and NF- $\mathrm{B}$ has been reported in several studies; Li et al (34) found that the treatment of hepatic stellate cells with AngII activated its receptor AGTR1, which subsequently increased the activity of $\mathrm{NF}-\kappa \mathrm{B}$; Du et al (35) reported that an AGTR1 antagonist inhibited the expression of $\mathrm{NF}-\kappa \mathrm{B}$, which then decreased the proliferation of breast cancer cells; and Ekambaram et al (36) suggested that AGTR1 overexpression may activate the $\mathrm{NF}-\kappa \mathrm{B}$ signaling pathway, and may promote cell proliferation, migration and invasion, as well as angiogenesis. In addition, AngII/AGTR1 exacerbated vascular calcification following the activation of $\mathrm{NF}-\kappa \mathrm{B}$, which induced the inflammatory response in human vascular smooth muscle cells (37). Therefore, it was hypothesized that, in EM, the upregulation of AGTR1 expression may activate the $\mathrm{NF}-\kappa \mathrm{B}$ signaling pathway, which may promote cell migration and proliferation to contribute to EM development, as well as the inflammatory response to induce symptoms of EM.

The present study also discovered that the expression of AGTR1 was regulated by estrogen. EM is known to be an estrogen-dependent disease; Galvankar et al (38) reported that estrogen was essential for the induction of EM, whereas Wang et al (39) suggested that estradiol may promote inflammation, and increasing expression of both $\mathrm{C}-\mathrm{X}-\mathrm{C}$ motif chemokine 12(CXCL12) and C-X-C Motif Chemokine Receptor 4 in human endometrial stromal cells, which contributes to EM pathogenesis. CXCL12 is a chemokine and plays a crucial role inflammatory reaction and cell migration (40). Moreover, low expression levels of estrogen and progesterone have been found in the serum and urine of women with EM $(41,42)$. In the present study, it was suggested that the estrogen/AGTR1 signaling pathway may be involved in EM pathogenesis. In stromal cells derived from human endometrial tissue, estrogen treatment decreased the expression levels of ATGR1, which subsequently inhibited NF- $\kappa \mathrm{B}$ activity, whereas the estrogen receptor modulator tamoxifen increased the expression levels of components of the ATGR $1 / \mathrm{NF}-\kappa \mathrm{B}$ signaling pathway. The regulatory effect of estrogen on AGTR1 expression has been found in other studies; Kooptiwut et al (43) suggested that, under high-glucose conditions, estradiol could decrease the mRNA expression levels of AGTR1 in pancreatic $\beta$-cells, while Gao et al (44) reported that estradiol could decrease the expression levels of AGTR1 in the uterine artery. Nickenig et al (45) also found that the AGTR1 protein density in rat aortic tissue was increased during estrogen deficiency. Therefore, during menstruation, the low levels of estrogen may induce an increase in AGTR1 expression, and then activate its downstream signaling pathway. However, in a study on ischemic injury of the heart in rats, Xue et al (46) argued that treatment with estradiol increased the expression levels of AGTR1in the heart. This paradoxical result suggests that these effects may be organ specific, and further research is required to understand the role of AGTR1 in EM. In addition, the present study was limited by the fact that it did not involve in vivo studies to verify the effect of AGTR1; thus, further investigations are required to understand the pathogenesis of EM.

In conclusion, the present study suggested that AGTR1 may contribute to the development of EM through the NF- $\kappa \mathrm{B}$ signaling pathway, and the increased expression levels of AGTR1 observed in EM tissue may be due to the low levels of estrogen during menstruation.

\section{Acknowledgements}

Not applicable. 


\section{Funding}

This study was supported by the National Natural Science Fund of China (grant no. 81503608) and the Natural Science Fund of Shijiazhuang city (grant no. 121461783).

\section{Availability of data and materials}

The datasets used and/or analyzed during the current study are available from the corresponding author on reasonable request.

\section{Authors' contributions}

$\mathrm{ZZ}$ and YY performed the experiments. ZZ, YY, XY and LH collected and analyzed the data. ZZ and JC designed the study and analyzed the data, drafted and reviewed the manuscript and supervised the entire study. YY designed the study, revised the manuscript and provided material support. All the authors have read and approved the final manuscript.

\section{Ethics approval and consent to participate}

Study protocols involving human subjects were approved by the Institutional Ethics Committee of The Fourth Hospital of Shijiazhuang City, and written informed consent was obtained from all subjects.

\section{Patient consent for publication}

Not applicable.

\section{Competing interests}

The authors declare that they have no competing interests.

\section{References}

1. Czyzyk A, Podfigurna A, Szeliga A and Meczekalski B: Update on endometriosis pathogenesis. Minerva Ginecol 69: 447-461, 2017.

2. Cramer DW and Missmer SA: The epidemiology of endometriosis. Ann N Y Acad Sci 955: 11-22; Discussion 34-16, 396-406, 2002.

3. Garcia-Velasco JA and Somigliana E: Management of endometriomas in women requiring IVF: To touch or not to touch. Hum Reprod 24: 496-501, 2009.

4. Diao R, Wei W,Zhao J, Tian F, Cai X and Duan YG: CCL19/CCR7 contributes to the pathogenesis of endometriosis via PI3K/Akt pathway by regulating the proliferation and invasion of ESCs. Am J Reprod Immunol 7: e12744, 2017.

5. Pazhohan A, Amidi F, Akbari-Asbagh F, Seyedrezazadeh E, Farzadi L, Khodarahmin M, Mehdinejadiani S and Sobhani A: The Wnt/ $\beta$-catenin signaling in endometriosis, the expression of total and active forms of $\beta$-catenin, total and inactive forms of glycogen synthase kinase-3 $\beta$, WNT7a and DICKKOPF-1. Eur J Obstet Gynecol Reprod Biol 220: 1-5, 2017.

6. Zhang Z, Ruan L, Lu M and Yao X: Analysis of key candidate genes and pathways of endometriosis pathophysiology by a genomics-bioinformatics approach. Gynecol Endocrinol 35: 576-581, 2019.

7. Park YA, Choi CH, Do IG, Song SY, Lee JK, Cho YJ, Choi JJ, Jeon HK, Ryu JY, Lee YY, et al: Dual targeting of angiotensin receptors (AGTR1 and AGTR2) in epithelial ovarian carcinoma. Gynecol Oncol 135: 108-117, 2014.

8. Watanabe Y, Shibata K, Kikkawa F, Kajiyama H, Ino K, Hattori A, Tsujimoto M and Mizutani S: Adipocyte-derived leucine aminopeptidase suppresses angiogenesis in human endometrial carcinoma via renin-angiotensin system. Clin Cancer Res 9: 6497-6503, 2003.
9. Hsieh YY, Chang CC, Chen SY, Chen CP, Lin WH and Tsai FJ: XRCC1 399 Arg-related genotype and allele, but not XRCC1 His107Arg, XRCC1 Trp194Arg, KCNQ2, AT1R, and hOGG1 polymorphisms, are associated with higher susceptibility of endometriosis. Gynecol Endocrinol 28: 305-309, 2012.

10. MacKenzie A: Endothelium-derived vasoactive agents, AT1 receptors and inflammation. Pharmacol Ther 131: 187-203, 2011.

11. Wei $X$ and Shao $X$ : Nobiletin alleviates endometriosis via down-regulating NF- $\kappa \mathrm{B}$ activity in endometriosis mouse model. Biosci Rep 38: BSR20180470, 2018.

12. Taniguchi F, Uegaki T, Nakamura K, Mon KY, Harada T and Ohbayashi T: Inhibition of IAP (inhibitor of apoptosis) proteins represses inflammatory status via nuclear factor-kappa B pathway in murine endometriosis lesions. Am J Reprod Immunol 79, 2018.

13. Diop-Frimpong B, Chauhan VP, Krane S, Boucher Y and Jain RK: Losartan inhibits collagen I synthesis and improves the distribution and efficacy of nanotherapeutics in tumors. Proc Natl Acad Sci USA 108: 2909-2914, 2011.

14. Block M, Fister S, Emons G, Seeber S, Gründker C and Günthert AR: Antiproliferative effects of antiestrogens and inhibitors of growth factor receptor signaling on endometrial cancer cells. Anticancer Res 30: 2025-2031, 2010.

15. Slopien R and Meczekalski B: Aromatase inhibitors in the treatment of endometriosis. Prz Menopauzalny 15: 43-47, 2016.

16. Polin SA and Ascher SM: The effect of tamoxifen on the genital tract. Cancer Imaging 8: 135-145, 2008.

17. Podolin PL, Callahan JF, Bolognese BJ, Li YH, Carlson K, Davis TG, Mellor GW, Evans C and Roshak AK: Attenuation of murine collagen-induced arthritis by a novel, potent, selective small molecule inhibitor of IkappaB Kinase 2, TPCA-1 (2-[(aminocarbonyl)amino]-5-(4-fluorophenyl)-3-thiophenecarboxamide), occurs via reduction of proinflammatory cytokines and antigen-induced T cell Proliferation. J Pharmacol Exp Ther 312: 373-381, 2005.

18. Chatterjee S, Malhotra R, Varghese F, Bukhari AB, Patil A, Budrukkar A, Parmar V, Gupta S and De A: Quantitative immunohistochemical analysis reveals association between sodium iodide symporter and estrogen receptor expression in breast cancer. PLoS One 8: e54055, 2013.

19. Livak KJ and Schmittgen TD: Analysis of relative gene expression data using real-time quantitative PCR and the 2(-Delta Delta C(T)) method. Methods 25: 402-408, 2001.

20. Reis FM, Petraglia F and Taylor RN: Endometriosis: Hormone regulation and clinical consequences of chemotaxis and apoptosis. Hum Reprod Update 19: 406-418, 2013.

21. Nehme A, Zouein FA, Zayeri ZD and Zibara K: An update on the tissue renin angiotensin system and its role in physiology and pathology. J Cardiovasc Dev Dis 6: 14, 2019.

22. Herr D, Bekes I and Wulff C: Local renin-angiotensin system in the reproductive system. Front Endocrinol (Lausanne) 4: 150, 2013.

23. Vinson GP, Teja R, Ho MM, Hinson JP and Puddefoot JR: The role of the tissue renin-angiotensin system in the response of the rat adrenal to exogenous angiotensin II. J Endocrinol 158: 153-159, 1998.

24. Yoshimura Y: The ovarian renin-angiotensin system in reproductive physiology. Front Neuroendocrinol 18: 247-291, 1997.

25. Brunswig-Spickenheier B and Mukhopadhyay AK: Local regulatory factors in regulation of ovarian function: Role of prorenin-renin-angiotensin-system. Indian J Exp Biol 41: 669-681, 2003.

26. Abraham F, Sacerdoti F, De Leon R, Gentile T and Canellada A: Angiotensin II activates the calcineurin/NFAT signaling pathway and induces cyclooxygenase- 2 expression in rat endometrial stromal cells. PLoS One 7: e37750, 2012.

27. Kowalczyńska LJ, Ferenc T, Wojciechowski M, Mordalska A, Pogoda K and Malinowski A: Endometriosis and RAS system gene polymorphisms: The association of ACE A2350G polymorphism with endometriosis in Polish individuals. DNA Cell Biol 33: 328-335, 2014.

28. Nakao T, Chishima F, Sugitani M, Tsujimura R, Hayashi C and Yamamoto T: Expression of angiotensin II types 1 and 2 receptors in endometriotic lesions. Gynecol Obstet Invest 82: 294-302, 2017.

29. King AE, Critchley HO and Kelly RW: The NF-kappaB pathway in human endometrium and first trimester decidua. Mol Hum Reprod 7: 175-183, 2001.

30. Kaponis A, Iwabe T, Taniguchi F, Ito M, Deura I, Decavalas G, Terakawa $\mathrm{N}$ and Harada T: The role of NF-kappaB in endometriosis. Front Biosci (Schol Ed) 4: 1213-1234, 2012. 
31. Luca M, Huang S, Gershenwald JE, Singh RK, Reich R and Bar-Eli M: Expression of interleukin- 8 by human melanoma cells up-regulates MMP-2 activity and increases tumor growth and metastasis. Am J Pathol 151: 1105-1113, 1997.

32. Nie J,Lu Y, Liu X and Guo SW: Immunoreactivity of progesterone receptor isoform $\mathrm{B}$, nuclear factor kappaB, and IkappaBalpha in adenomyosis. Fertil Steril 92: 886-889, 2009.

33. Park H, Kim SH, Cho YM, Ihm HJ, Oh YS, Hong SH, Chae HD, $\mathrm{Kim} \mathrm{CH}$ and Kang BM: Increased expression of nuclear factor kappa-B p65 subunit in adenomyosis. Obstet Gynecol Sci 59: 123-129, 2016

34. Li X, Zhang YJ, Meng Y, Zhou GS and Zhang ZS: Effect of angiotensin II type 1 receptor and angiotensin-converting enzyme gene silencing on nuclear factor-kappaB activity in hepatic stellate cells. Nan Fang Yi Ke Da Xue Xue Bao 29: 402-404, 2009 (In Chinese).

35. Du N, Feng J, Hu LJ, Sun X, Sun HB, Zhao Y, Yang YP and Ren H: Angiotensin II receptor type 1 blockers suppress the cell proliferation effects of angiotensin II in breast cancer cells by inhibiting AT1R signaling. Oncol Rep 27: 1893-1903, 2012.

36. Ekambaram P, Lee JL, Hubel NE, Hu D, Yerneni S, Campbell PG, Pollock N, Klei LR, Concel VJ, Delekta PC, et al: The CARMA3-Bcl10-MALT1 signalosome drives NFאB activation and promotes aggressiveness in angiotensin II receptor-positive breast cancer. Cancer Res 78: 1225-1240, 2018.

37. Jia G, Stormont RM, Gangahar DM and Agrawal DK: Role of matrix Gla protein in angiotensin II-induced exacerbation of vascular calcification. Am J Physiol Heart Circ Physiol 303: H523-H532, 2012.

38. Galvankar M, Singh N and Modi D: Estrogen is essential but not sufficient to induce endometriosis. J Biosci 42: 251-263, 2017

39. Wang X, Mamillapalli R, Mutlu L, Du H and Taylor HS: Chemoattraction of bone marrow-derived stem cells towards human endometrial stromal cells is mediated by estradiol regulated CXCL12 and CXCR4 expression. Stem Cell Res 15: 14-22, 2015.
40. Dotan I, Werner L, Vigodman S, Weiss S, Brazowski E, Maharshak N, Chen O, Tulchinsky H, Halpern Z and Guzner-Gur H: CXCL12 is a constitutive and inflammatory chemokine in the intestinal immune system. Inflamm Bowel Dis 16: 583-592, 2010.

41. Cunha-Filho JS, Gross JL, Bastos de Souza CA, Lemos NA, Giugliani C, Freitas F and Passos EP: Physiopathological aspects of corpus luteum defect in infertile patients with $\mathrm{mild} / \mathrm{minimal}$ endometriosis. J Assist Reprod Genet 20: 117-121, 2003.

42. Smith MP, Keay SD, Margo FC, Harlow CR, Wood PJ, Cahill DJ and Hull MG: Total cortisol levels are reduced in the periovulatory follicle of infertile women with minimal-mild endometriosis. Am J Reprod Immunol 47: 52-56, 2002.

43. Kooptiwut S, Wanchai K, Semprasert N, Srisawat C and Yenchitsomanus PT: Estrogen attenuates AGTR1 expression to reduce pancreatic $\beta$-cell death from high glucose. Sci Rep 7: 16639, 2017.

44. Gao H, Yallampalli U and Yallampalli C: Protein restriction to pregnant rats increases the plasma levels of angiotensin II and expression of angiotensin II receptors in uterine arteries. Biol Reprod 86: 68, 2012.

45. Nickenig G, Baumer AT, Grohe C, Bäumer AT, Grohè C, Kahlert S, Strehlow K, Rosenkranz S, Stäblein A, Beckers F, et al: Estrogen modulates AT1 receptor gene expression in vitro and in vivo. Circulation 97: 2197-2201, 1998.

46. Xue Q, Xiao D and Zhang L: Estrogen regulates angiotensin II receptor expression patterns and protects the heart from ischemic injury in female rats. Biol Reprod 93: 6, 2015

This work is licensed under a Creative Commons

Attribution-NonCommercial-NoDerivatives 4.0 International (CC BY-NC-ND 4.0) License. 